\title{
Gabriel de Zayas (1526-1593). Notas biográficas
}

\author{
Pedro Rodríguez *
}

Gabriel de Zayas, el amigo e interlocutor, junto al rey, de don Francés de Álava durante su embajada en París ${ }^{1}$, es también un personaje cuya biografía es poco conocida. González Palencia escribía en 1946: «hay otro secretario, notable en los días de Felipe II, de quien apenas se tienen noticias, y cuyo origen empieza a conocerse ahora. Se trata de Gabriel de Zayas " ${ }^{2}$. La realidad es que el ilustre autor apenas aporta

* Profesor de la Universidad de Navarra.

- Estas notas se escribieron con ocasión de editar la "Colección de don Francés de Álava", que se encuentra en el Archivo de los Marqueses de San Millán, hoy en el Archivo Municipal de San Sebastián. Vid. Rodriguez, P. y Rodríguez, J., Don Francés de Álava y Beamonte. Correspondencia inédita de Felipe II con su Embajador en París (1564-1570). San Sebastián 1991. Bajo la sigla CFA remitimos a los documentos publicados en este libro.

${ }^{2}$ González Palencia, A., Gonzalo Pérez, Secretario de Felipe ll. Madrid 1946, I. pág. 225. - Se han planteado la figura de Zayas y aportan datos: LOPEZ DE TORO, E., LaS epistolas de Juan Verzosa, "Clásicos españoles", II. Madrid 1945, págs. 29s (texto de la epístola 20 dedicada a Zayas), 196-200 (datos biográficos) y en el índice la voz "Zayas"; González Palencia, A., I, págs. 125s y 132-157; y Escudero, J. A., Los Secretarios de Estado y del Despacho. Madrid 1969, l, págs. 135-155. Vid. también Marañón, G., Antonio Pérez. El hombre, el drama, la época. Madrid 1958, 6. ${ }^{a}$ ed., 2 vol. (vid. en el índice la voz "Zayas"). Como para don Francés de Álava, en el caso de Zayas la fuente fundamental para conocerle es la abundante correspondencia que se conserva, editada y no editada. El elenco de las cartas de Zayas ya publicadas en la Colección de Documentos inéditos para la Historia de España (CDIHE) puede verse en Escudero, J. A., ibidem, en notas a pie de página. En los legajos de las secciones Estado y Consejo de Italia de Simancas hay por todas partes otras muchas cartas suyas, "que debidamente estudiadas y publicadas acabarían de perfilar la personalidad de Gabriel de Zayas, el cual espera la mano del investigador que lo dé a conocer en su integridad” (LÓPEZ DE TORO, E., op. cit., pág. 196). 
nada sobre su origen. Se suele decir que era vasco ${ }^{3}$. López de Toro apunta a que es aragonés: «Debió descender - escribe- de la familia de los Zayas que, según las crónicas, fueron a la conquista de Calatayud en el año 1120, y que allí quedaron, constituyendo una de las casas más distinguidas, conforme lo prueba Zurita en sus Anales. Pero este Gabriel no aparece por ninguna parte. A juzgar por la época debió ser un segundón, porque el dueño del vínculo se llamaba don Gaspar» ${ }^{4}$. Con todo, tampoco parece que esto vaya bien encaminado. La realidad es que los autores no saben ni dónde ni cuándo nació el secretario de Estado.

Los documentos de la «Colección de don Francés de Álava» van a contribuir a orientarnos. Allí vemos a Gabriel pidiendo a don Francés pequeños favores familiares para el «veedor de la gente de guerra en Granada» Tomás de Zayas, su mujer y sus niñas ${ }^{5}$. Este Tomás aparece perfectamente situado dentro del linaje de los Zayas establecidos en Andalucía -Écija (diócesis de Sevilla) y Córdoba- desde la época de la conquista ${ }^{6}$. Por otra parte, sabemos por la correspondencia del nuncio con el secretario de Estado en Roma que «el Secretario Gabriel de Zayas es de la diócesis de Sevilla, y hace ya 40 años que sirve a S. M. in habito clericale" ${ }^{7}$. Todo apunta a que nuestro secretario pertenece al linaje andaluz de loz Zayas, que era probablemente de Écija y clérigo desde 1546. Un inventario de los bienes de Zayas hecho unos meses antes de su muerte nos lo confirma: allí se alude a "un relicario grande que embió la emperatriz de Çayas mi señor con otros dos menores, el uno quue embió su merced a la Capilla de los Çayas de Écija, el otro...” ${ }^{8}$.

Más todavía, gracias a la documentación del proceso del célebre fray Bartolomé de Carranza, editada por J. I. Tellechea, podemos casi asegurar el año de su nacimiento y otras muchas cosas interesantes. El arzobispo de Toledo había llamado a Zayas a declarar como testigo y éste dijo ante el juez instructor el día 17.XI.1562 que tenía 36 años y que era ya oficial del secretario real Gonzalo Pérez en 1548, cuando el príncipe Felipe escribió a fray Bartolomé proponiéndole que fuera su confesor; y que esto lo sabe --agrega- porque Gonzalo Pérez "ordenó" la

3 Vid., por ejemplo, LAPEYRe, H., en Historia General de España y América, VI. Madrid 1986, pág. 16.

${ }^{4}$ LOPEZ DE TORO, E., op. cit., pág. 196.

5 Vid. CFA, doc. $166 / 3$ y $168 / 7$.

- Vid. Real Academia de la Historia (RHA), Col. Salazar y Castro, ms. H-11, ff. 11441155 , especialmente 1149s.

${ }_{7}$ Madrid 11.XI.1586: Archivo Secreto Vaticano (ASV), Spagna, vol. 33, ff. 81 ss.

${ }^{8}$ Archivo Histórico de Protocolos de Madrid (AHPM), prot. 300, f. 868v. 
carta y él la escribió «de su mano» ${ }^{9}$. También nos informa Zayas de la respuesta del dominico, "escusándose con su insuficiencia para tomar sobre sí una ánima de Rey» ${ }^{10}$. Nació, pues, Gabriel el año 1526 y comenzó muy joven su trabajo en la Secretaría de Felipe $1 /$-casi al tiempo de tonsura clerical, cuando tenía 20 años-y siguió al príncipe en sus viajes. É mismo nos informa que estuvo en Inglaterra los años 15541555 en el séquito que acompañaba a Felipe II en su enlace con María Tudor.

Zayas, en efecto, entra en la vida política a la sombra de Gonzalo Pérez, que le otorga una creciente confianza y se refiere a él como «mi criado" ${ }^{11}$-Zayas a él como «mi Señor»— y termina designándolo, junto a su hijo Antonio y a Juan Luis de Alzamora, su albacea testamentario ${ }^{12}$. Se comprende que después de tantos años de trabajo y fatigas conjuntas, la muerte de Gonzalo le afectara profundamente ${ }^{13}$.

En la correspondencia del Rey Católico con don Francés de Álava vemos a Zayas sustituyendo a Gonzalo Pérez en el refrendo de la firma del rey ya en 1564, es decir, en vida de Pérez ${ }^{14}$. A la muerte de Gonzalo -ocurrida el 12 de abril de $1566^{15}$-, el nuncio Castagna escribe al cardenal Reomano que hace tiempo que Zayas está de hecho al frente de la Secretaría de Estado y que "se crede restará al suo loco" ${ }^{16}$. Sin embargo, después de la muerte de Gonzalo, vemos que también su hijo, el tristemente célebre Antonio Pérez - que contaba entonces 25 años-, comienza a acreditar la firma del rey en los documentos oficiales. Desde

9 Fray Bartolomé de Carranza. Documentos históricos, ed. TellecheA, J. I., III, págs. 218-219. Por cierto, Gonzalo Pérez dice en su declaración que «no recuerda» nada sobre el tema.

10 Ibidem

11 González Palencia, A., op. cit., pág. 592.

12 Ibidem, pág. 225.

${ }_{13}$ «Aunque la carta que V. E. me scribió los días pasados rescibí toda la merced y favor posible, no he respondido antes porque después que fallesció Gonzalo Pérez mi señor, que haya gloria, he andado y aún ando agora muy falto de salud" (Zayas a García de Toledo, Segovia 4.IX.1566, en CDIHE, vol. 30, pág. 396.

${ }^{14}$ Vid. CFA, doc. 12 y 13. Zayas agrega después de su firma: "Por secretario", dato éste que no he visto señalado por los especialistas. Las primeras cartas refrendadas por Zayas y Antonio Pérez referidas en Escudero, J. A., op. cit., pág. 135, son de 18 de agosto de 1566. Cabrera de Córdoba escribe: «Zaias, oficial muy antiguo y que en ausencia de Gonzalo Pérez había negociado con el Rey y servido mucho" (CABRERA DE CORDOBA, L., Felipe II, Rey de España, escrita en 1619, Madrid 1876-77, I, 490s).

15 Serrano, L., Correspondencia diplomática entre España y la Santa Sede durante el pontificado de San Pio V. Madrid 1914, I, pág. 179.

${ }^{16}$ Ibidem, p. 196. 
el 19 de octubre de 1566 ambos entraban ya en las sesiones del Consejo de Estado, aun sin tener el título de secretarios reales, que el rey les confirió finalmente con fecha de 17 de julio del año siguiente ${ }^{17}$. El plan de Felipe II era dividir en dos la Secretaría de Estado - Gonzalo Pérez fue, según Pellicer citado por Arteaga ${ }^{18}$, el «primero y único secretario de Estado"- y con fecha de 8 de diciembre de ese mismo año ejecutaba el plan, asignando a Zayas los asuntos "de esa Embaxada [la de Francia] y de las Cortes del Emperador e Inglaterra" - así lo comunicaba dos dias después a don Francés de Álava ${ }^{19}$ - y a Antonio Pérez los negocios de Italia.

Marañón, tomándolo de Cabrera de Córdoba ${ }^{20}$, cuenta que Zayas influyó notablemente en la designación de Antonio "por gratitud a la memoria de su padre Gonzalo [...]; perjudicándole él, pues la secretaría íntegra debía haber pasado a sus manos». Y, sin embargo, la ambición de Antonio Pérez puso en graves aprietos a Zayas casi desde el principio: ya en 1568 vemos a Zayas hablando confidencialmente a don Francés de «la insolencia y los excessos de mi colega" ${ }^{21}$. En 1576, por presiones de don Juan de Austria - que se movía en la línea de Éboli y ahora de Antonio Pérez-, se le había quitado a Zayas, en beneficio del hijo de Gonzalo, buena parte de la negociación de Flandes ${ }^{22}$. Pero la ambición de Pérez iba incrementándose y su enfrentamiento con Mateo

17 El título de secretario de Zayas en Escudero, J. A., op. cit., Ill, págs. 624-626. Hizo el juramento el 26 de agosto. La "Instrucción» que le entrega el rey para el ejercicio de su cargo puede verse en $\mathrm{BL}$, Addition, 28.360, ff. 112-117.

18 Arteaga, Breve noticia de Gonzalo Pérez, en CDIHE, 13, págs. 531-549. Vid. la discusión de esta afirmación en Escudero, J. A., op. cit., I, pág. 127s.

19 Vid. CFA. doc. 73.

20 Cabrera, L., op. cit, pág. 490s; Marañón, G., op. cit., I, pág. 33.

21 Vid. CFA, doc. 63/6. En realidad Antonio Pérez no perdonaba a Zayas haberse interpuesto entre él y la «herencia» de su padre. Esta carta de Pérez al gobernador de Milán es reveladora: "Yo he entendido que el Secretario Çayas ha embiado a perdi todos los papeles del Conde de Luna, de quando fue Embaxador acerca del Emperador y en el Concilio de Trento, que están en poder del Secretario Neyva. $Y$ aunque yo tengo todos los registros de todos ellos como despachados por mano de mi padre, todavía por no tocar por esta razón al Secretario Cayas, he querido supplicar a V. Exc. ${ }^{\text {a }}$, con la occasión deste correo, que me haga merced, como en todo, de mandar hazer un despacho o despachos de todos los que huviere de embiar a su Magestad, remitidos a su propia mano, y a las mías con otra cubierta, para que se los dé, que él los mandará remitir a quien fuere servido. Lo qual no lo scrivo a $V$. Exc. ${ }^{a}$ porque tenga neçessidad de los papeles, sino porque haviendo de venir a manos de algún Secretario, es razón que por haver sido despachados por las de mi padre vengan a las mías" (AGS, Estado, leg. 1227, núm. 164). Nótese que la materia de los papeles del conde de Luna correspondía a la negociación de Zayas y no a la de Pérez. Posiblemente, éste le había puesto dificultades a Zayas para consultar los registros de su padre que eran su coto personal.

22 Vid. Escudero, J. A., op. cit., I. págs. 139 y 150. 
Vázquez, el poderoso secretario personal de Felipe II, era cada vez mayor. Zayas, que era buen amigo de Vázquez, se vio metido sin buscarlo en la tormenta de los años 78 y 79 . Proyectaba el rey entregar de nuevo a una misma persona los dos negociados de la Secretaría de Estado, separados a la muerte de Gonzalo Pérez. Antonio Pérez pretendía acumular además la Secretaría del Consejo de Italia ${ }^{23}$, que había vacado por muerte del comendador Diego de Vargas. El rey parecía dispuesto en un primer momento a dársela ${ }^{24}$, aún sabiendo que la acumulación ponía en manos de Pérez todos los asuntos de Italia. Pero aconsejado, al parecer, por el conde de Chinchón, terminó ofreciendo a Pérez hacerse cargo de los dos negociados de la Secretaría de Estado- dejaba Zayas el del Norte- y a éste fue al que dio el rey la Secretaría del Consejo de Italia. Pérez lo estimó una derrota. Ya en marzo escribía Vázquez: «poco ha se encontraron Zayas y Antonio Pérez, creo que en la galería, y no se descubrieron ni hablaron el uno al otro" ${ }^{25}$. $Y$ en julio: "Zayas y Antonio Pérez también diz que no se hablan" ${ }^{26}$. El día 13 de julio juró Zayas su puesto en el Consejo de Italia y el 28 era arrestado Antonio Pérez, quedando en suspenso en el ejercicio de sus funciones, haciéndose cargo de ellas Juan de Idiáquez ${ }^{27}$. Hernando de Vega -que informa a diario a Vázquez mientras éste está en El Escorial- le escribe unos días después:

«El nuevo Secretario [Idiáquez] ayer estuvo conmigo. Zayas grande amigo es de V. m. y muy alegre me parece que está; no sé lo que hay. La muger de Antonio Pérez fue ayer a estar con su marido y sus amjgos han estado alegres y hoy no lo están" ${ }^{28}$.

La operación de los años 76-79, que acabó con la caída de Antonio Pérez, fue interpretada por algunos también como una pérdida de posi-

${ }^{23}$ Ibidem, págs. 158s. No confundir el Consejo de Italia con la sección «ltalia» de la Secretaría de Estado: ésta es la que tenía Pérez desde la muerte de su padre.

${ }^{24}$ El rey escribía a Pazos, presidente del Consejo de Castilla, Madrid 7.III.1579: “Tratad oy con el personage [el duque de Medina Sidonia] qué se habrá de hazer con Çayas" (Texto en Muro, Gaspar, Vida de la Princesa de Eboli. Madrid 1877, Apéndices pág. 43).

${ }^{25}$ Mateo Vázquez al Rey, Madrid 16.lll.1579; en Muro, G., op. cit., Apéndices, pág. 115.

${ }^{26}$ Mateo Vázquez al Rey, Madrid 3.VII.1579; en Muro, G., op. cit., pág. 115.

${ }^{27}$ «Ya don Juan Idiáquez a aceptado lo que os dije el otro dia, que es lo del Consejo de Guerra en propiedad y lo de la Secretaría de Estado en el entretanto que yo no ordenase otra cosa" (El Rey a Granvela, 28.VIIl.1579, citado en MuRo, op. cit., pág. 201.

${ }^{28}$ Hernando de Vega a Vázquez, sept. 1579; en Muro, G., op. cit., Apéndices, pág. 84 , 
ción de Zayas: «è servitore molto antico del Re, et oggi è stato battuto di maniera che non è piú stimato da persona» ${ }^{29}$. La observación del embajador veneciano era ya exagerada en 1577, cuando la hizo, y falsa en 1579. Pero es indudable que Idiáquez era el que había sustituido a Antonio Pérez en los grandes negocios de Estado, y no Zayas, cuya estrella declinó con el tiempo: Vázquez y Pérez, primero, y después Vázquez e Idiáquez serán los secretarios fuertes ante el rey. Zayas, también por su carácter, siempre estuvo en la segunda fila en medio de las turbulencias de Estado.

La Instrucción dada a Zayas con ocasión del cambio es interesante en este sentido. El rey comienza diciendo que al haberos "escogido a vos, Gabriel de Çayas, por nuestro Secretario en los Reynos de Nápoles, Sicilia y Estado de Milán, se pudiera escusar daros Instrucción, pues en el Consejo de Estado havéys servido con tanta fidelidad, limpieza y cuydado, como a todos es notorio, de que estoy satisfecho»; a pesar de ello, estima el rey conveniente determinar, pensando en los sucesores de Zayas, la manera de proceder en este Consejo. Al terminar, Felipe II le dice a Zayas que «porque por vuestra edad e indisposiciones no podréys todas vezes assistir en Consejo, ni leer ni decretar lo que se acordare», ha pensado que colabore con él y entre en Consejo Francisco de Idiáquez, al que acaba de nombrar secretario real a estos efectos ${ }^{30}$. Como se ve, debía estar avejentado - teniendo sólo 53 años-, su salud no era buena y se pensaba ya en la sucesión. Pero Zayas aguantó bien y desde 1579 sirvió hasta su muerte la Secretaría del Consejo de Italia y el rey le entregó además la de Portugal, a donde se trasladó con don Felipe en los años 1580-83. Su salario era de 100.000 maravedíes. Desde finales de 1592 estaba ya enfermo en cama y otorgó testamento. El 7 de julio de 1593 lo completó con un codicilo ${ }^{31}$ y el 13 entregaba Zayas su alma al Señor ${ }^{32}$. Sabemos por sus disposiciones testamentarias que dotó una capelianía perpetua en el Hospital de San Lucas y San Nicolás, de Alcalá de Henares, en cuya capilla fue enterrado ${ }^{33}$.

${ }^{29}$ Así se lee en una Relatione delle cose di Spagna del 1577, anónima, atribuida a un embajador veneciano. Citada por Escudero, J. A., op. cit., I, pág. 139.

30 Texto de la «Instrucción», 20.X.1579, en AHN, Estado, leg. 1893.

31 AHPM, prot. 300; el testamento en fols. 859-865, el codicilo, fols. $857 \mathrm{~s}$; detallado inventario de sus bienes al morir y del paso a los legatarios, fols. 877-893.

32 «Morse el Secr. $^{\circ}$ Zayas al principio di questa settimana, et S. M. ha comandato si continui l'offitio con li medesimi ufficiali del Secretario nella medesima Casa Zayas" (EI Nuncio a Roma; Madrid 17.XII.1593, en ASV, Spagna, vol. 43, fol. 185). El día 16 los albaceas hacian ya el citado inventario. La secretaría del Consejo de ltalia estuvo vacante dos años y, al cubrirse en 1595, se dividió en tres secretarías (Milán, Nápoles y Sicilia).

${ }_{33}$ Donó además al dicho hospital una hermosa colección de reposteros (vid. AHPM, prot. 300 , fol. $857 \mathrm{v})$. 
En la correspondencia editada de Zayas se encuentran escasas referencias a su vida familiar y cotidiana. Sí, en cambio, numerosas alusiones a sus parientes, por desgracia sin señalar el grado de parentesco, to que facilitaría avanzar en el conocimientos del secretario de Estado. Abundan, como era frecuente entre los hidalgos de la época, los militares: sabemos de Juan Montiel de Zayas, de quien el secretario dice, al recomendarlo al virrey de Nápoles, que «es cosa mía» ${ }^{34}$; y de Jerónimo Zayas, "deudo de v. m." ${ }^{35}$, capitanes del ejército español en Nápoles y Portugal respectivamente. Zayas comunica a Mateo Vázquez en 1587 la muerte de otro Jerónimo de Zayas ${ }^{36}$, también capitán y pariente del Secretario. De Tomás, el "veedor de la gente de guerra en Granada», y su familia ya hemos hablado, y sabemos también del Alférez Gaspar de Zayas, por cuyo comportamiento en la batalla de Mons, en los Países Bajos, Lope Zapata felicita al secretario de Estado ${ }^{37}$. No podemos establecer el grado de parentesco del secretario con todos estos parientes, por lo que se preocupa: desde obtener unos juguetes para las hijas del veedor hasta que trasladen de mar a tierra a Jerónimo de Zayas en Lisboa.

Mención especial merece su sobrino Alonso de Zayas Ostos, que vivía con él en su casa y era uno de sus oficiales, al que dejó 1.000 ducados de renta y toda su biblioteca, más su colección de retratos y pinturas, que conocemos perfectamente por el inventario que hicieron sus testamentarios ${ }^{38}$. Tenía en Gabriel mucha fuerza la vinculación a su tronco familiar y en la correspondencia de la Nunciatura en España pueden seguirse los esfuerzos de Zayas hasta lograr que se concediera altar privilegiado para «la capilla de nuestro linaje» ${ }^{39}$, que ya sabemos se encontraba en Écija.

34 Vid. Zayas a García de Toledo. Madrid 4.X.1566, en CDIHE, 30, pág. 396.

${ }^{35}$ Duque de Alba a Zayas, Lisboa 29.IX.80, en CDIHE, 33, pág. 86. Numerosoas referencias en este volumen de la CDIHE. Murió de la peste en Lisboa en 14.V.1581.

${ }^{36}$ Murió en el Peñón de Gibraltar, según leemos en Zayas a Vázquez, Madrid 2.l.1587, en British Library (BL), Addition, 28.363, f. 28.

${ }_{37}$ Vid. Lope Zapata Zayas. Bruselas 29.VII.1572; en CDIHE, 36, pág. 98. Información sobre esta batalla en BL, Addition, 28.387, fols. 90-97.

${ }_{38}$ Este Alonso de Zayas pasó a la Secretaría de Nápoles en 1595. Zayas, al morir, fue espléndido con sus oficiales de la Secretaría de ltalia, según se lee en su codicilo testamentario. Conocemos sus nombres: aparte de Alonso de Zayas, eran Juan López de Zárate, oficial mayor y Juan de Atienza.

${ }_{39}$ En ASV, Spagna, vol. 11, fol. 305, hay una nota ológrafa de Zayas al nuncio, de $5 . V I .1578$, de la que están tomadas estas palabras. El envío del breve con la concesión del privilegio le fue anunciado de Roma al nuncio en carta de 10.11 .1579 (ibidem, vol. 2, fol. $309 \mathrm{v}$ ). 
Zayas era clérigo, pero no nos consta que hubiera recibido Órdenes. Tuvo carta de hermandad con los cartujos, que le gestionó don Francés de Álava en París y le concedió el prior Dom Bernardo Carasse y el Capítulo General de la Orden reunido en Chartreuse. En ella se dice que le ha propuesto el P. Bernardo de Castro, prior de la Casa de Santa María del Paular, «erga quam praecipue devotionis et affectus vos habere omnino intellegimus" ${ }^{40}$. Era, como don Francés de Álava, un hombre piadoso al estilo de la época ${ }^{41} \mathrm{y}$ al morir se preocupó de repartir sus bienes entre sus oficiales y criados, en obras de caridad y en ordenar sufragios, especialmente "por las ánimas de mis padres e abuelos y difuntos y bienhechores, y por las personas que tengo algún cargo y obligación, y por todas las animas del purgatorio".

La Relatione anónima arriba citada, complaciente con Antonio Pérez y crítica con Zayas, no puede menos de reconocer que éste no se enriqueció con el cargo:

"Non è molto ricco, piglia tutto quelio che gli è dato, et sebene è assai avanti con la sua età, non lassa per questo ii suoi piaceri».

No se sabe qué es lo que pretende insinuar el anónimo, pues la honestidad de Zayas no ha sido desmentida.

Vázquez de Prada - que conoce en profundidad a los hombres de Felipe II - ha calificado al secretario de Estado como hombre justo y honrado ${ }^{42}$. Era un patriota al estilo de la época y -en expresión de Cabrera de Córdoba- "secretario fidelísimo" al rey ${ }^{43}$, "diestro y muy religioso» ${ }^{44}$. Don Francés decía de él que era «dechado para todos los de su profesión» ${ }^{45}$. Una idea del crédito que tenía ante Felipe II se ve en el hecho de que éste en 1568 lo incluyera en una lista de media docena

${ }^{40}$ AGS, Estado, $\mathrm{K} 1527$, n. ${ }^{\circ}$ 67. Expedida en la Cartuja mayor, "nostro sedente Capitulo generali», 14 de mayo de 1571 .

${ }_{41}$ Hablando del traslado de Huesca a Alcalá de los restos de los santos Justo y Pastor, escribe Ambrosio de Morales: "Todo el negocio pasaba por manos de Gabriel de Zayas, Secretario de Estado de su Magestad y de su Magestad y de su Consejo, el cual desde el principio que se trató este santo negocio, había hecho en él mucho y agora particularmente con gran devoción destos santos y con mucho cuidado y autoridad trató por orden de su Magestad todo lo que convenía" (MORales, Ambrosio de, Vida de los Santos Justo y Pastor, pág. 71, citada por Redel, E., Ambrosio de Morales. Estudio biográfico. Córdoba 1908, pág. 141).

${ }_{42}$ Voz «Felipe II", en Gran Enciclopedia Rialp, IX. Madrid 1971, pág. 827.

${ }^{43}$ Cabrera, L. op. cit., III pág. 246.

${ }^{44}$ Cabrera, L. op. cit., IV, pág. 264

${ }^{45}$ Vid. Negociaciones con Francia (NF), XI/n. ${ }^{\circ} 1186$, pág. 379. 
de españoles que podían ser candidatos para el capelo cardenalicio ${ }^{46}$. Dentro de los dos partidos o líneas de acción política en la época de Felipe II, que capitaneaban el príncipe de Éboli, Ruy Gómez de Silva, y el duque de Alba, Fernando Álvarez de Toledo, Zayas militaba sin duda en el que acaudillaba el duque ${ }^{47}$, al que admiraba profundamente y con el que llegó a tener una gran amistad y trato confidencial.

Zayas unía a la fidelidad una devoción grande a la Sede Apostólica, a la que buscaba apoyar cuanto podía desde sus importantes posiciones en la Corte del Rey Católico. Todos los nuncios en Madrid, desde Juan Bautista Castagna - con el que tuvo gran amistad--, daban testimonio a Roma de la bondad del secretario Real. Escribía Ormanetto en 1572:

«Egli è huomo che a faticato et fatica tutta via per it benefitio publico, essendo Secretario di Stato" ${ }^{48}$.

Y el obispo de Novara en 1586:

«Hora è il primo Secretario del Consiglio d'Italia, ove passano quasi tutte le cosa che io tratto per servitio di nostro Signore. Egli è conosciuto per uno degli migliori huomini di questa Corte, et ogni dii ho molti servitii et amorevoli avisi da lui » ${ }^{49}$.

En este contexto Zayas esperaba que de Roma le hicieran merced de algún beneficio, pero tampoco él era hombre con arte para el medro personal. Lo tenía muy bien visto el nuncio obispo de Piacenza: como es un hombre - dice ${ }^{50}$ - «pieno di bontà et di discretione, et che non farebbe mai un officio per se stesso, è necessario che la ricognitione et mercede li venga di motto proprio di S. Beatitudine».

${ }^{46}$ Nota marginal autógrafa de Felipe II a una carta que le dirige don Juan de Zúñiga desde Roma, 12.X.1568. Los otros de la lista son Rodrigo de Castro, Francisco de Soto y Salazar, Gaspar de Quiroga y Juan de Ovando, miembros del Consejo de la Inquisición. Vid. Serrano, L. op. cit., II, pág. 941.

47 Léase detenidamente CFA, doc. 63/6, en el que Zayas, de manera un tanto críptica, pero con lenguaje tal vez transparente para don Francés, se refiere a la tensión entre Ruy Gómez y el duque de Alba, estando por medio "la insolençia y los excesos de mi colega", es decir Antonio Pérez, y a la violenta situación en que se encuentra Zayas, entre dos fuegos.

${ }^{48}$ Madrid 1.V.1572, en ASV, Spagna, vol. 16. fol. 79. Respuesta de Roma: «E stato molto grato a N. Signore l'intender l'amorevolezza ch'il Secr. ${ }^{\circ}$ Zayas mostra a V. S. ${ }^{2}$ e il servitio che fa a le cose di $\mathrm{S}$. Santità et di questa Santa Sede in tutto quello che può" (10.X.1572, ibidem, vol. 15, fol. 73v)

${ }^{49}$ Madrid 11.XI.1586, ibidem, vol. 33, fol. 81.

${ }^{50}$ Madrid 17.X-1579, ibidem, vol. 22, fol. 389. 
Los nuncios se daban cuenta de la ayuda inestimable que era aquel hombre, y pedian alguna merced para él. Pero da la impresión de que en Roma, como tantas veces ha ocurrido en la historia, mimaban a los más problemáticos y se desentendían de los más seguros. Interesante esta página del nuncio Sega:

\begin{abstract}
«Et poiche io sono a parlare di canonicati et di Secretari, V. S. Illma. saprà ch'il povero vecchio Secr. ${ }^{\circ}$. Zayas, da bene quanto l'oro, et che professa d'essere servitoe antico di S. Stà. fin dall'andata de S. Btne. in Fiandra, havendo vedute queste provisioni per Escovar, per il fratello di Gastello et per Matheo Vasquez è venuto da me à fare mezza querela della sua infelicità; non sapendo in somma attribuire ad altro questa sua disgrazia di non avare attenuto un quattrino di rendita delia Sede Apostolica in tanti anni di sua servitù, nel qual tempo non pretende d'essere stato servo inutile appreso di questa Maestà, se non che non habuerit hominem qui cum turbata esset aqua posuerit ipsum in piscinam ${ }^{51}$. Supplico però V. S. llima à restare servita di rapprasentare à S. Stà. la giusta querela di questo servo fedele, accioche presentandosi l'occasione d'altra vacanza si ricordi di lui, che veramente lo merita. Et favoriscami, la supplico, di dirlo a S. Btne. in mio nome ancora, assicurandola che tra le Ministri di $S$. Mtà questo mi è riuscito sempre molto amorevole e verdadiero in tutte le cose di ch'egli alla giornata mi ha potuto avertire» ${ }^{52}$.
\end{abstract}

Desde Roma no se hizo nada. Años después Felipe II le concedió una pensión de 800 ducados sobre los frutos de la diócesis de Cuenca. Zayas ahora a lo único que aspira es a que de Roma no le cobren derechos de expedición de la bula... ${ }^{53}$ No hemos podido comprobar si obtuvo esta merced. Ni un quattrino, como decía el nuncio. Todo lo que consiguió el secretario en 40 años de servicio llenos de lealtad a la Santa Sede fue el altar privilegiado, del que antes hemos hablado, para la capilla de su linaje.

Pero Zayas era sumamente ahorrativo y fue acumulando rentas, en concreto, 4.000 ducados de un censo en Burgos más algunas rentas eclesiásticas: la que ya conocemos de Cuenca -1.000 ducados dice el

51 El texto latino es casi a la letra del Evangelio de San Juan, 5, 7.

52 Madrid 26.VII.1578, ASV, Spagna, vol. 11, fol. 376v.

53 Vid. Nuncio al Card. Rusticucci, Madrid 4.VI.1587, ibidem, vol. 33, fols. 266-268v. 
inventario, no 800 -, otra de 400 ducados en Sevilla ${ }^{54}$ y otra de 200 en Pamplona. Es los inventarios se describe su casa en la Villa y Corte:

"Yten, unas casas principales en que el dicho secretario bibía, que son en la parroquia de San Pedro en esta Villa y alindan de la una parte con casas de doña Catalina de Soto y casas de doña Catalina de Uydobro, y por las espaldas con la muralla de la villa. Yten, otras casas pequeñas, que están en la dicha parroquia lindando con las dichas casas principales y con casas de Pedro de Ribera” ${ }^{55}$.

En esta casa - «que les costó 3.400 ducados y ha gastado en ella más de otros 1.600 "- - era donde tenía instalada la oficina de la secretaría real, y como en ella vivía también Alonso de Zayas, alí se continuó trabajando, muerto Gabriel, hasta que el rey en 1595 creó la triple secretaría de Milán, Nápoles y Sicilia. Así se describe una de las piezas del inventario: «dos cofrecillos encorados, el uno lleno de legajos de villetes de Çayas mi señor al Rey con su respuesta». ¿Dónde se encontrará hoy este tesoro?

Zayas fue buen humanista como su maestro Gonzalo Pérez ${ }^{56}$. Gracias a sus disposiciones testamentarias hemos podido establecer que estudió en la Universidad de Alcalá de Henares, con la que mantuvo un estrecho vínculo, que no quiso interrumpiera ni siquiera la muerte: en aquella villa —dice en su testamento- «me mando sepultar por aver sido hijo de aquella Universidad y tenerle grande amor e voluntad». Zayas debió estudiar en Alcalá al menos los cursos $1545-46$ y $1546-47^{57}$ y sus grandes amigos eran en su mayoría de la Complutense. Sabemos que

54 De ésta, sobre las rentas del arzcbispado de Sevilla, gozaba ya en 1571, fecha en la que otorga poder en favor de Diego Díaz Becerril, vecino de Sevila, para que pueda cobrar esta pensión (vid. AHPM, prot. 270, fol. 812v; ante Gaspar Testa, 4.VIII.1571). En esta misma fecha y ante el mismo escribano otorgaba otro poder para cobrar en Nápoles otra pensión anual de 100 escudos sobre las rentas del arciprestazgo de Retamura, que le concedió el rey al proveerlo en Juan Vicenzo Palagino. Vid. ibidem, fol. 812. Esta pensión no la retenía al morir. nuncio.

55 Ibidem, fol. 886. Estaban, pues, en la zona de Costanilia de San Pedro y calle del

56 Vid. abundantes datos en las citadas páginas del epistolario de Verzosa.

57 1545-46 es el último curso de la primera estancia de Ambrosio de Morales en Alcalá, al que Zayas califica de «amigo y hermano del tiempo de los estudios»; 1546-47 fue cuando estudió en Alcalá Calvete de Estrella, que califica a Zayas de "viejo compañero" («tuus vetus sodalis": LOPEZ DE TORO, E., op. cit., pág. 198). En 1548 Zayas ya trabaja de oficial con Gonzalo Pérez. 
tenía una buena biblioteca ${ }^{58}$ y que mantuvo abundante intercambio cultural y literario con los mejores humanistas de su tiempo: tuvo estrecha relación con Juan de Verzosa, como ya dijimos, con Cristóbal Plantino, con don Diego Hurtado de Mendoza, con Calvete de Estrella, con Pedro de Fuentidueñas, etc. ${ }^{59}$; era amigo personal de Arias Montano - se conserva la correspondencia entre ambos ${ }^{60}$ - de Jerónimo de Zurita ${ }^{61}$, de Ambrosio de Morales. Interesante la amistad con este último: en carta a Zurita ya citada alude Zayas a su regreso de Alcalá, «adonde me avía ido por me recrear un poco con Ambrosio de Moraies, amigo y hermano del tiempo de los estudios" ${ }^{62}$. La amistad era recíproca y viene testificada con hermosas palabras por el maestro Morales ${ }^{63}$. Al morir Zayas había en su casa una treintena de "ymáxines y pinturas", entre ellos, claro está, retratos del emperador, de Felipe II y del duque de Alba ${ }^{64}$.

Su sello - una cuadriga veloz - tenía como divisa las palabras latinas Medio tutissimus ibis ${ }^{65}$, es decir, si quieres ir seguro, ve por el centro. Y su reloj de uso personal —regalo de don Francés de Álavaestaba enmarcado por estas otras castellanas: "La más incierta es la

${ }^{58}$ Detallado inventario en AHPM, prot. 300, fols. 888-892.

59 Vid. LOPEZ DE TORO, E., en los lugares arriba citados.

${ }^{60}$ Una buena parte ha sido publicada en el vol. 41 de los CDIHE.

${ }^{61}$ Zayas admiró a Zurita como escritor y apoyó a fondo, desde su posición junto al rey, la publicación de los famosos Anales de la Corona de Aragón. Vid. en DormeR, D. J., y Ustarroz, J. F., Progresos de la historia en el Reyno de Aragón. Zaragoza 1680, págs. 519 y 180 , sendas cartas de Zayas a Zurita sobre el tema, fechadas en 6.VII.1562 y 8.V.1563. En otra carta posterior a Diego de Guevara (5.XII.1563, ibidem, pág. 152) justifica sus gestiones en pro de los Anales, aparte de los méritos intrínsecos de la obra, en «aver sido mi padre que sea en gioria muy su amigo".

${ }_{62}$ Zayas a Zurita, 8.V.1563. Una vuena biografía es la obra de REDEL. E., ya citada. Morales era de Córdoba, como muchos de los Zayas, pero 12 años mayor que el secretario.

63 «Tratando yo algunas veces familiarmente, por nuestra mucha amistad, con el señor Gabriel de Zayas, Secretario de Estado del Rey nuestro Señor y dignísimo, por su prudencia y gran ser en todo lo bueno, de cargo tan principal y quejándome desto (alude a la mala crianza de los hijos) me satisface con mucho donaire diciendo: que no me espante, porque muchos señores el día de hoy tratan de criar en sus hijos sólo los cuerpos y no las almas, y yo le respondo entonces que a esa cuenta criarán buenos animales" (Morales, Ambrosio de, Discurso sobre lo mucho que importa la buena crianza de los hijos, citado en REDEL, pág. 141). sobrino.

64 Inventario en AHPM, prot. 300, fol. 888. La biblioteca y los cuadros pasaron a su

${ }_{65}$ Puede verse, por ejemplo, en su carta al cardenal de Como, Madrid 4.VII.1583, en ASV, Spagna, vol. 24, fol. 392. López de Toro piensa que estas palabras eran su «ex libris»: así figuran de su puño y letra en un libro de la Biblioteca Nacional (signatura: R/ 22.366), seguidas de la firma "Gab. Çayae et amicorum 1571». 
cierta» ${ }^{66}$. Una lección de prudencia, aquel lema, para abrirse paso y subsistir en aquella compleja Corte (in medio: ¿entre Pérez y Vázquez? ¿entre Vázquez e Idiáquez?); y un recordatorio, el del reloj, de la provisionalidad del momento presente. Dos rasgos sin duda de la manera que tenía de afrontar la vida.

Pero sabemos, sobre todo, gracias a la correspondencia con el embajador español en Francia, el citado don Francés de Álava, la confianza y el afecto que caracterizaban la amistad entre ambos, hasta el extremo de que el señor de la Casa de Álava -como sabemos- había encomendado el secretario real vigilar la educación de su único hijo, mientras él se movía por Francia. Don Francés llegó a tener tanta estima por Zayas que, insensiblemente, tendía a despachar los negocios con él más que con el rey, por lo que Zayas hubo de hacerle esta sabia advertencia, en la que aplica la prudencia - y la cautela - que refleja su lema:

\begin{abstract}
«V. S. ${ }^{a}$ por me honrrar y favoresçer ha dado en escrivirme tantos negocios de Estado, y a las vezes más que en las cartas de su Magestad, y esto no conviene la auctoridad dellos, ni aun a mí tampoco, porque no se imagine por ventura que yo lo procuro y que es ambición mía, de que directa ni indirectamente querría ser notado, pues sabe V. S. ${ }^{a}$ de mi ánimo, que por la gracia de Dios espero muy poco en ella, y assí conviene que de aquí adelante escriva $V$. S. ${ }^{a}$ al Rey todos sus negocios, y a mi los familiares, y si ocurriere que yo le diga algo separadamente de los otros, este tal podrá venir en las mías, que éste es buen camino para V. S. ${ }^{a}$ y para mì" ${ }^{67}$.
\end{abstract}

Al cabo de los años, en plena campaña de Portugal, don Francés escribirá a Zayas una de sus cartas entre amigos, en la que alude «a lo que merece el sincero amor que yo he tenido $y$ tengo a todo quanto a $v$. m. tocas ${ }^{68}$.

Sirvan estos datos para situar de alguna manera la personalidad de este hombre que, junto al rey, llena las páginas de la «Colección de don

${ }^{66}$ Es éste un dato tomado de la CFA. Don Francés le gestionó el «relogillo» en París. (Vid. CFA, doc. 219). Se lo envió por fin en octubre de 1569: «El primero que despacharé lo llevará [se refiere a un Breviario para el cardenal Espinosa] con el relox de v. m., que diz que será singular pieça, y otro relogillo para la muger de don Juan de Acuña" (Álava a Zayas, Tours 29.X.1569, en AGS, Estado, K 1512, n. ${ }^{\circ} 138$ ). En el inventario, fol. 883 se lee: "un reloxillo pequeño con campanilla». Era el de don Francés.

67 CFA, doc. 168/3.

6s Setúbal 25.VIl.1580, en CDIHE, vol. 32, pág. 296. 
Francés de Álava", las cuales aportan rasgos numerosos sobre la vida y talante de este personaje, tan ligado a Felipe II y tan relacionado con la política y la cultura de su tiempo. Entre ellos, su peculiar sentido del humor, que le hacia llamar a la Confesión de Augsburgo la "Confusión» augustana ${ }^{69}$, unido al sentido trascendente y providencialista de los acontecimientos, que le llevaba a confortar a don Francés de Álava -que se deprimía ante la grave situación de la Iglesia en Francia-, diciéndole: «Buen ánimo, y Dios delante, y una higa para toda la herejía del universo" ${ }^{70}$.

69 Vid. CFA, doc. 164/1.

${ }^{70}$ Ibidem, doc. $183 / 13$ 